\title{
Making a claim for services: Supporting young people's engagement with services
}

\author{
Kimberley Dewhurst, Robyn Munford and Jackie Sanders Massey University, Aotearoa New Zealand
}

\begin{abstract}
INTRODUCTION: Young people who experience significant adversity use multiple services (child welfare, youth justice, mental health, and education support services). Engagement with services can facilitate access to support and resources to mitigate the risks these young people face in their every-day lives. This article draws on the findings from a qualitative study which sought to examine the factors that either facilitated or inhibited young people's engagement with services. The young people had complex needs and had used multiple services from an early age.
\end{abstract}

METHODS: The study used in-depth interviews to explore young people's service experiences. A thematic inductive analysis identified key themes. The concept of making a claim for services emerged as an explanatory device to understand the processes of service engagement.

FINDINGS: Making a claim for services was a critical first step in young people's engagement with services, representing an ongoing interactive process between young people and service providers. Three key elements comprised a successful claim for services: young people's needs meeting service entry criteria; personal agency; and, relevant and meaningful service responses.

CONCLUSION: The findings indicate that making a claim for services is a dynamic process and that a cornerstone of effective practice with vulnerable youth involves social workers establishing meaningful relationships with young people. Social workers who make a positive difference in young people's lives are open to the different ways in which young people express their needs and support them to participate as active partners in interventions.

KEYWORDS: young people, adversity, services, support, agency

AOTEAROA

NEW ZEALAND SOCIAL WORK 29(1), 4-15.

CORRESPONDENCE TO: Robyn Munford

R.Munford@massey.ac.nz
It is well recognised that young people with complex needs will be users of multiple services. Young people who are involved with child welfare and youth justice services are also likely to require education support and mental health services (Maschi, Smith Hatcher, Schwalbe, \& Rosato, 2008). Recent public discussion has highlighted the need for consideration to be given to how the well-being of the most vulnerable children and young people can be enhanced (Office of the Children's Commissioner, 2015). This discussion brings into focus the idea that vulnerable youth need to be able to access services, as a particular set of resources, to support them to achieve a successful transition into adulthood (Aaltonen, 2013). There is ongoing debate about how involvement with multiple services actually supports vulnerable youth to mitigate risks in their lives and successfully navigate their transition into adulthood. Some studies (see, for instance, Ungar, Liebenberg, Dudding, Armstrong, \& van de Vijver, 2013) have identified that the quality of service provision, rather than the quantity of services, is more important in shaping outcomes for youth, and that increased service use may not actually substantively reduce the risks that young people face. 
Studies such as these indicate that the way in which services are delivered, including the way in which they support young people's engagement in interventions, is an important factor in supporting youth who are multiple service users to access the resources they need to mitigate risks in their lives.

This article draws on the findings of a qualitative study which sought to add to the knowledge about what constitutes positive service engagement for vulnerable youth. This research focused on building an understanding of young people's perspectives on their service experiences. The study answers the question: What is the process by which young people become successfully engaged with services? The youth had complex needs and, as a consequence, had been users of multiple services from a young age. There are numerous studies examining young people's engagement with services; however, few studies examine the experiences of young people across multiple service domains. The article begins with an overview of the relevant literature regarding young people's engagement with services and a discussion of the theoretical concepts that informed the study. It then provides an outline of the methodology utilised in the qualitative study, and then moves to a discussion of the key findings from the study. The article concludes with a discussion of the implications for practice.

\section{Young people's engagement with services}

Engagement with services is an important way of boosting the resilience resources around vulnerable young people; services provide a set of resources which can help young people to mediate risk in their lives. Researchers have identified the factors which influence young people's engagement with services; that is, what facilitates or inhibits service engagement. Young people's initial experiences in becoming involved with services have the potential to influence their long-term engagement with the service; for example, when services are perceived by young people as being welcoming, empowering and respectful, they are more likely to remain engaged with the service (French, Reardon, \& Smith, 2003). As Prior and Mason (2010, p. 12) note:
'Engagement' suggests a set of objectives around developing young people's personal motivation and commitment to involvement in activities. It implies that passive involvement is not enough.

Researchers have identified that relationships between clients and practitioners are the cornerstone of effective practice (Ruch, 2005). With regard to vulnerable youth, the relationships they are able to form with their service providers and the perceptions they have about the services they access, will contribute to either facilitating or hindering service engagement. Relationships which are empowering, authentic and respectful, and where young people feel safe and supported, have been found to facilitate young people's positive engagement with services (McLeod, 2007). A key focus for practitioners is ensuring that relationships with service providers do not replicate the power imbalances that exist between young people and adults who have not kept them safe and who have let them down; instead, these relationships should seek to offer young people the freedom to safely share their experiences and reflections in their own words (French et al., 2003).

When considering young people's engagement with services within the Aotearoa New Zealand context it is important to consider issues surrounding cultural identity and belonging. The principles of Te Tiriti o Waitangi (partnership, participation and protection) remind us of the importance of understanding young people's relationships within their iwi, hapu and whānau (Munford \& Sanders, 2011). Of significance for this study are the high numbers of Māori young people in care (Office of the Children's Commissioner, 2015). The challenge for social workers is to 
ensure that services are culturally relevant and that whānau are active partners in decision-making about their young people. Effective services adopt social work models that draw on cultural beliefs and practices and support young people to remain connected with their whānau, hapu, and iwi, and to express their cultural identity in ways that are meaningful to them.

Also of significance in building an understanding of the nature of service engagement for vulnerable young people, is exploring the idea of agency including young people's ability to make sense of their circumstances and to have a voice in decisions that have impacted on their life circumstances. In thinking about agency, the idea of "bounded agency" (Evans, 2007, p. 92) is useful in understanding how young people's agency is tempered, but not fully controlled by social structures and their social positioning as "not adults" (Evans, 2007). Bounded agency recognises that youth exercise agency in defining and negotiating their lives and futures, but that their ability to do this is limited by their social, cultural, economic and political contexts (Aaltonen, 2013, p. 377; Evans, 2007, pp. 92-93). For young people who have faced significant and sustained challenges, such as prolonged exposure to abuse and neglect, violence, addictions, disengagement from education, and mental health issues, factors that limit their ability to exercise agency may be even more pronounced than for other youth who have experienced more normative transitions throughout their lives (Aaltonen, 2013; Munford \& Sanders, 2015). Associated with these life experiences are also their experiences of services where these services have not always facilitated access to meaningful support and resources (Sanders \& Munford, 2014a).

Young people's beliefs about what service provision might entail, their beliefs about whether they need help, and their views of service providers (for example, whether service providers are seen as friendly and accessible) have all been found to influence young people's decisions to engage with services (French et al., 2003; Jones, 2011). Research has indicated that factors such as stigma, labelling by diagnosis, coercion, assessments that young people felt were too quick to allow practitioners to develop a full understanding of what was happening for them, and a lack of personal control over service intervention options, all negatively impacted on their engagement with services (French et al., 2003). Moreover, given their circumstances, vulnerable young people may have little support to help them make sense of service delivery; such as service entry criteria, levels of entitlement, and the types of support that are available to them (Berzin, 2010, p. 493).

When vulnerable youth face barriers which inhibit their engagement with services, it may mean that they are unable to make a claim for services and receive the support they need. The quality of experiences young people have with services is central in boosting the resilience processes they have access to (Ungar et al., 2013). When young people are unable to locate services they perceive as empowering, respectful and relevant, their access to the supportive resources that services can provide (for example, emotional support; physical resources such as transport and housing; and supportive relationships with nonfamilial adults) is undermined. For many young people this becomes an entrenched pattern that compromises their ability to achieve well-being and to realize better outcomes.

On the other hand, when young people feel service providers are available, authentic, youth-focussed, respectful and trustworthy, they are more likely to engage with them. These factors align with positive youth development (PYD) approaches to service delivery (Lerner, Almerigi, Theokas, \& Lerner, 2005). PYD approaches adopt the view that adolescence is a time of significant growth and potential, and view youth as resources to be developed, rather than as problems to be managed (Lerner et al., 2005, 
p. 11; Sanders \& Munford, 2014). In practice, services utilising PYD approaches work in ways that empower youth, actively involving them in decision-making and encouraging them to exercise their personal agency. Services utilising PYD approaches also work in ways that account for young people's wider circumstances such as their cultural identity, and family/whānau circumstances. It has been argued that such an approach to service delivery will enable youth to receive services that are respectful, empowering and well-attuned to their wider circumstances (Lerner et al., 2005). The ideas outlined here informed the design and focus of the current study.

\section{The study}

The purpose of the study was to investigate young people's experiences of becoming engaged with services and to understand the factors that influenced their engagement. It sought to answer the question: What is the process by which young people become successfully engaged with services? The study drew on qualitative interviews $(n=109)$ with youth who were multiple service users. The interviews with the young people were collected for the Pathways to Resilience Project (the Pathways Study) between 2009 and 2013 (Sanders et al., 2013). The Pathways Study was a mixed-methods study that sought to understand the service experiences of young people (aged 13-17) who were using two or more services (child welfare, youth justice, education support and mental health) in five geographical locations.

The Pathways Study was approved by the Massey University Human Ethics Committee. Protocols ensured that research processes were sensitive and respectful, that young people were well informed about the study and gave their own written consent to participate in the research. Young people were recruited from services and, while these services gave permission for the researchers to contact young people, consent was sought directly from the young people. To protect anonymity and confidentiality, nominating organisations did not know who had given consent.

The qualitative interviews captured information about young people's life experiences, including experiences of family/whānau, school, community and services; relationships; exposure to risk and adversity; understanding of health and well-being; and their views on what did or what could assist them in addressing their challenges and achieving their goals (Sanders et al., 2013). Through thematically analysing these interviews, the study sought to develop an understanding of young people's experiences of service engagement. The study was informed by a social constructionist epistemology. Social constructionist thought prioritises the role of human agency and discourse in shaping the social world, and recognises that the experience of being is subjective (Berger \& Luckman, 1966). Data analysis was underpinned by the social constructionist assumption that the youth held valid subjective interpretations of their experiences and their social world. This epistemological framework aligned with contemporary theories that inform social work practice with young people; these perspectives increasingly emphasise the importance of exploring and understanding the ways in which youth experience and mediate their social worlds (Aaltonen, 2013). Of importance was exploring with the young people their understanding of the individual, relational and contextual factors that had shaped their experiences, including their ability to exercise agency.

Inductive thematic analysis was used to analyse the data (Sanders et al., 2013). Initial themes were drawn from the interviews where youth explored issues such as: gaining access to services, their experiences across services (statutory and NGOs, voluntary and involuntary), experiences of meaningful support from services, and the role of family/whānau in 
service engagement. Through recursively moving between the raw data and emerging themes, a list of themes that reflected the lived realities of these young people was generated. Conceptual maps were developed in this process allowing exploration of the relationship between the themes and also the literature once the data had been analysed. The concept of "making a claim for services" emerged from the analysis as an explanatory device that captured the processes of service engagement.

\section{The young people}

Data from 109 youth were drawn on for the analysis presented in this article. The young people were aged between 13 and 17 years. Fifty-six (51.4\%) were male, and $53(48.6 \%)$ were female. A system of prioritised ethnicity was used to determine the ethnicity of the youth (Cormack \& Robson, 2010). Young people could identify as many ethnicities as they felt accurately described their sense of cultural identity. Any youth who identified Māori as one of their ethnicities were classed as Māori. Young people who identified as having a Pacific identity were coded as Pacific youth, providing they did not also identify as Māori. Young people who did not identify Māori or Pacific ethnicities but who did identify Pākehā or other Western European identities were classified as Pākehā. Young people who identified any other ethnicity were classified as being of "other" ethnicity. Sixty-three youth (57.8\%) identified as Māori; 28 (25.7\%) as Pacific; $14(12.8 \%)$ as Pākehā, and four (3.7\%) identified as other ethnicity.

The young people were involved with two or more services across the service spectrum (i.e. child welfare, youth justice, alternative and specialised education, and mental health services). A total of 70 young people (64.8\%) were involved with child welfare services; 72 $(66.7 \%)$ were involved with youth justice; 95 $(88 \%)$ were involved with education services; and $68(63 \%)$ were involved with mental health services.

\section{Findings: Making a claim for services}

The concept of making a claim for services emerged in the data analysis process as a heuristic device which explained young people's experiences of engaging with services. Making a claim for services was identified as a critical first step in a process of successful engagement with services. Service engagement involved an ongoing, interactive process between clients and service providers of developing an understanding of client needs, what services could offer, and what a meaningful and relevant service response entailed. Regardless of whether service involvement was voluntary or involuntary, the youth sought to maintain a sense of control over their engagement with services. They sought to have meaningful connections with their social workers and they wanted their views and concerns to be heard and to be involved in decisions about interventions and service delivery. Making a claim for services comprised three essential elements which interacted to shape young people's service engagement:

- young people's needs and service entry criteria;

- personal agency; and

- relevant and meaningful service responses.

This section considers each of these three elements of making a claim for services, using quotations from the young people's interviews to illustrate key points. All identifying information within the quotations has been changed, and pseudonyms have been used to protect the privacy of the young people.

\section{Young people's needs and service entry criteria}

Services in Aotearoa New Zealand operate within the context of a number of legislative and policy frameworks. These frameworks determine factors such as client eligibility for particular services, and the ways in which services can be provided to clients. 
Successful claims for services required that services could intervene within their mandate. Young people had to be able to communicate their needs to service providers. This required service providers to be receptive to young people's attempts to communicate their needs and to form relationships with young people that enabled them to feel empowered, respected and listened to.

Many of the young people reported challenges in communicating their needs to service providers. Without a clear understanding of young people's needs, service providers could not intervene in ways that supported the young person. In order to support young people to communicate their needs, service providers needed to be open to the different ways in which young people may attempt to let them know that they needed help and support. A large number of the young people used their behaviour to show adults in their lives that they needed support, as Byron captured below:

I guess I started misbehaving [at school], started being a dick to my teacher, coz of all the home problems and shit. I guess I just took it out on everybody else. (Byron, 15 years)

When service providers were not receptive to young people's attempts to communicate their needs, the young people took from this response that services could not provide the support they needed which meant opportunities for early intervention were missed. This was illustrated by Armani and Renee in the following quotations:

They [service providers] can help me, but I knew they couldn't help me in the way that I wanted... I asked [them] to put me in rehab... And they reckoned they were sorting it out but it never happened. (Armani, 15 years)

We were telling [child welfare services] for ages that we were getting abused, until we moved ourselves. Like we didn't go through the lawyers and that, we just packed our bags and just moved. They [child welfare services] were like, "oh, why did you move?" and we were like, "we've been trying to tell you."

(Renee, 15 years)

In order to make a successful claim for services, young people's needs had to meet service entry criteria. However, service providers needed to be open to how young people communicated their needs and this involved drawing upon the expertise of young people in developing an understanding of their needs. Byron's spoke of how his social worker listened to him and supported him to identify his needs and to develop a plan to meet these needs and achieve his goals. As a consequence he felt valued and this, in turn, had a positive impact on his engagement with services:

Ruth [youth justice social worker] was talking about, "so what do you want to do with your life?" and I was like, "well, I don't want to be a loser. I want to be [a famous person]." And I thought she would just take it as a joke and be like, "nah, you're a loser, you're never going to get anywhere" like all the other [service providers and school staff] had. But she was like, "so do you want to go back to school?" And I was like, "yeah, but no school will accept me". She was like "no, I think we can arrange that." And within two weeks she got me enrolled in school. I was rapt. (Byron, 15 years)

Byron's story represents those of many of the young people in the study who reported that they wanted service providers to see them as a whole person, and view their challenges in the context of their personal histories. For example, Kaitlyn (15 years) explained that she distrusted workers who did not understand her "back story". For young people like Byron and Kaitlyn, the challenges for which they were referred to services stemmed from deeper issues at home or within their community, such as chronic neglect and abuse. The young people wanted service providers to understand the impact of these experiences when they were 
establishing ways they could intervene to help the young people. As Kaitlyn expressed, these experiences made you angry. Young people who had similar experiences to Kaitlyn put up barriers and pushed workers away. These young people were actually asking for someone to listen to them and respond to their issues. Service providers had to find a way through these barriers and this required them to be flexible in the strategies they used to engage with young people.

\section{Personal agency}

Successful claim-making required opportunities for young people to exercise their agency and have a sense of control about their engagement with services; there had to be opportunities for youth to be partners in the interventions that were offered even if service involvement was mandated, for example, youth justice custodial sentences. This could be achieved through youth participating in decisionmaking, for example through Family Group Conferences (FGCs). The active involvement of clients as partners in service interventions is important because clients hold important expertise regarding what will work in their lives and, ultimately, it is they who will make changes (Ruch, 2005). Relationships with workers were central in empowering young people to exercise their personal agency and participate in decision-making processes.

The desire to exercise agency over their involvement with services was pervasive across the young people's interviews. Due to the "bounded" nature of young people's agency (Evans, 2007, p. 92), young people required support to exercise their agency in positive ways. Natasha's experiences illustrate this. Natasha had been involved with child welfare services since she was 10 , and had repeatedly run away from her placements. When Natasha was 16, a new social worker involved her in planning for her independence. Natasha explained the impact this had:
I never had a plan. I was running away for the hell of it. I've only been stable for like the last six months ... Coz now I have a plan, I have a goal, something to work towards. And now that I've got that, I feel so much better coz I don't have to wonder why I'm not getting anywhere. (Natasha, 16 years)

In addition to having positive relationships with service providers that enabled them to participate in decision-making about their service involvement, young people reported that they wanted to retain a sense of control over their engagement with services. Many of the young people were supported to do this, for example when service providers asked them about their hopes and goals, and planned interventions around these. However, some of the young people felt that they were not listened to and that service providers were unable to adequately respond to their needs. These young people sought control over their engagement in other ways, for example, by refusing to talk to service providers about what they were experiencing or by behaving in ways that were challenging for workers to manage. Chelsea explained how she sought to reclaim control over her engagement with service providers after a series of episodic interventions that did not address the underlying issues with her family/whānau that were affecting her behaviour:

They [youth justice services] didn't know what to do with me. So it was like, oh she keeps offending, okay, we'll send her to counselling, we'll put her on a drug and alcohol course. We'll do what we did with all the others. I would pull out, sometimes I'd be like "no, I'm not talking to you, I want a different worker"... It's a pretty immature thing. I was kind of like stirring with them. Just kind of going, I won't see both sides. (Chelsea, 16 years)

Young people like Chelsea found that one way they could be in control of their service engagement was to behave in challenging ways that pushed their workers to find new ways of engaging with them. In contrast 
to this, some of the young people shared experiences of being supported to retain control over their service engagement, even when they did not have a choice about actually being involved with the service. For example, Mel was involved with a drug and alcohol counsellor as part of a Court Order:

She'd [counsellor] just take me out for just a normal day, yeah. She'd take me to the mall or to get a munch or something or just drive around and talk... It just gave me heaps of time to open up, yeah and she wasn't pushy... Coz she wanted to get to know me before I started saying stuff. (Mel, 15 years)

The desire to retain control over their engagement with services and to exercise their agency in their interactions with service providers was pervasive across the young people's interviews. Even when the young people had mandated involvement with services (for example, youth justice services), they sought control over their engagement, for example, by behaving in ways that gained the attention of workers. Strong, positive relationships with service providers were important in empowering young people to engage with services at their own pace and in encouraging them to participate in decision-making. This helped young people to feel a sense of control over their engagement with services and helped them to feel confident to seek the particular interventions they felt would meet their needs.

\section{Relevant and meaningful service responses}

When young people were able to communicate their needs to service providers and exercise personal agency in their engagement with them, they were able to negotiate access to relevant and meaningful services. This third element of successful claim-making reflected that young people had created a shared understanding of their needs with service providers. Getting the right help at the right time was important to the young people. However, a service response which was relevant to the young person's needs and meaningful within their wider circumstances (including their cultural context and beliefs) could not be activated if the first two elements of making a claim for services (communicating needs and exercising personal agency) were not achieved.

Many of the young people reflected on the importance of service providers understanding their needs. Jake and Natasha shared the following reflections about what makes a good worker:

Somebody who understands your needs. (Jake, 17 years)

Ones that can connect with you... You just have to be able to talk to them about anything, coz if you can't talk to them they're no good to you. (Natasha, 16 years)

The idea of a worker understanding young people's needs was central to their ability to make a successful claim for services. Young people wanted to feel that their workers "heard" them and understood their perspective. Many of the youth reported that their needs changed regularly; they lived in unstable environments and had volatile relationships with people in their daily lives. While these young people tried hard to build a shared understanding of their needs with service providers, many felt that the workers did not understand the consequences of their decisions, such as plans not being followed through. This was illustrated by Zane's experiences of involvement with child welfare services where he experienced inconsistent service responses:

Every time something would happen, they would put me in a house and everything would go sweet, then someone will say something or something will happen and boom, they shut down part of the plan. The only part that's keeping me going, the only bit that's wanting me to stay good. (Zane, 15 years) 
When young people like Zane experienced their plans being changed regularly (the thing that kept him hopeful), without their input, they felt disempowered and felt that their social workers did not understand them and their circumstances. Being let down yet again exacerbated their feelings of distrust of adults and of services. Other young people reflected that their service involvement was irrelevant to them and did not meet their needs as workers did not really understand their underlying challenges; for example, workers not understanding the impact of unstable living environments. This situation would cause other disruptions for young people such as disruption to school attendance as they tried to manage the challenging issues at home. As time passed for them, other young people became despondent about whether things would change; they felt that there was no point in them continuing to behave in ways that met service providers' expectations, as they had no goals that they wanted to achieve or believed they could actually achieve.

As well as wanting service providers to understand their needs, young people wanted social workers to help them understand why they could not always receive the support that they asked for; they wanted to understand service providers' rationale for the decisions they made. This was illustrated by Tama:

They [social workers] were straight up, instead of trying to do the "I will see," it was "nah you can't do that so," and I said "oh all good" instead of trying to lie to you and keep your hopes up waiting for ages and it's not even gonna happen. That's what I liked about them, they're straight up. (Tama, 16 years)

For young people like Tama, it was important that social workers not only understood their needs, but helped them to understand how service providers were constrained in the decisions they could make and the resources they could provide to youth. Young people appreciated this honesty and social workers being "straight up" with them as this enabled them to establish positive relationships with trusted adults, something that had been missing for many of the young people in this study. The social workers who made a difference were committed to working with young people to find relevant services and to supporting these young people to remain engaged with interventions that had the potential to create meaningful and positive change for these young people.

\section{Discussion: Practice implications}

The findings from this study offered a number of insights into the ways in which young people made a claim for services and the ways in which service providers can support young people to positively engage with services. Whether their involvement with services was voluntary or mandated, young people wanted to be actively involved in determining what support they needed, and in shaping how that support was delivered to them. In making a claim for services, young people needed to learn how to communicate their needs in ways that service providers understood as helpseeking. Youth also required opportunities to exercise their agency, through being supported to participate in decision-making and retain a sense of control over their involvement with services. Finally, young people and service providers had to build a shared understanding of their needs so that relevant and meaningful services could be put in place.

Young people appreciated those service providers who were willing to support them to be active partners in their engagement with services. Service providers needed to listen carefully to young people's efforts to communicate their needs, involve them in decisions, and work to build a shared understanding of young people's needs and their wider circumstances and the ways in which services could meet those needs. Engagement was not static for the young people; rather, they experienced times when they were more engaged and less engaged 
with services. It was important that service providers recognised engagement as an ongoing process rather than a singular event, and made the effort to connect with young people throughout the challenges they faced.

An early assessment of needs and risks is an initial step in service providers' interactions with clients. Identification of needs provides practitioners with a foundation upon which they can base their future work with clients (Coulshed \& Orme, 2006). The needs of the young people in this study were complex, and often went beyond the initial issue that they presented in their first contact with services. For example, a number of young people were referred to services for behavioural challenges; however, their behaviour was influenced by a wide range of challenges at home or at school, and that resolving these challenges would be more supportive for them than a narrow focus on their behaviour alone. Suspending judgement and taking the time to explore the wider factors influencing young people's behaviours and lives may be challenging for practitioners, many of whom may have limited time to spend with individual young people.

However, the experiences of the young people in this study underscore the importance of constructing young people as deserving of the time and attention it takes to understand their perspectives of what they need (Aaltonen, 2013). It was important that service providers were receptive to young people's efforts to communicate their needs. It is well recognised that relationships between social workers and young people are fundamental in supporting young people to engage with a service and that open, supportive relationships between practitioners and young people are the foundation of effective communication (McLeod, 2007). The same was true for the young people in this study. However, the challenges the young people in this study faced in communicating their needs and forming relationships with service providers suggests that this is an aspect of practice which could benefit from further attention.
Many of the young people did not have a choice regarding service involvement in their lives. Some were involved with child welfare services due to concerns about their care and well-being, or were involved with youth justice services as a result of offending. Others required mandatory support from mental health services due to concerns about self-harm or alcohol and drug misuse. Some young people were also required to attend alternative education services after being excluded from school, or required support from specialised education services throughout their schooling. Even when the young people were not voluntarily involved with services, they wanted to have some control over their engagement. They wanted meaningful connections with their social workers and other workers, such as tutors and youth workers, and wanted their views and concerns to be seen as important when decisions were being made. Relationships that empower young people to be active participants in interventions, and allow them to retain a sense of control over their involvement with service providers have been observed to have a positive impact on young people's engagement with services (Jones, 2011; McLeod, 2007). It has been suggested by various authors (for example, McLeod, 2007) that relationships between vulnerable youth and service providers should be egalitarian, empowering, and enduring, and that service providers should be seen by young people as accessible and available. This is supported by the findings of this study; the young people who had relationships with their service providers where they were empowered to exercise their agency, involved as partners in the interventions, and which were long-lasting, had more positive experiences of engaging with services.

This study has shown that it is important to recognise the substantial risks and challenges young people who are multiple service users face in navigating a safe pathway through adolescence and into adulthood. It is fundamental for those who work with vulnerable young people to form supportive, 
trusting relationships with these youth. Service providers were key people in the life stories of these young people. Young people responded positively to service providers who connected with them, gave their concerns and hopes consideration in decisions about interventions, respected their cultural beliefs and supported them to exercise their agency in their involvement with services. This aligns with other research on working with vulnerable young people (for example, Aaltonen, 2013; French et al., 2013) and indicates an ongoing need for practitioners to involve vulnerable young people in decision-making and planning for interventions.

\section{Limitations}

The findings reported on in this article were drawn from one qualitative interview with young people and capture their perspectives at one point in time.

\section{Conclusion}

The findings in this study have implications for practice with young people who have experienced adversity over their lifetime. It reinforces important roles for social workers in forming meaningful and authentic relationships with young people. What was evident from the experiences of the young people in this study was that their engagement with services is an ongoing, dynamic and complex process. The concept of making a claim for services was shown to provide a useful heuristic device for conceptualising young people's engagement with services highlighting three important aspects of this engagement: young people's needs and service entry criteria, personal agency, and relevant and meaningful service responses. The findings indicated that effective services are socially and culturally relevant. Practitioners who make a positive difference for young people are open to the different ways in which young people express their needs; these practitioners support young people to participate as active partners in the interventions that are offered. When services work well, young people are involved with decision-making processes, and communication between service providers and young people is open and honest. Importantly, when resources and interventions are relevant to young people's needs as they are understood by the young people, it is more likely that young people will successfully engage in services and that positive change will be achieved.

\section{Funding}

We thank the Ministry of Business, Innovation and Employment for funding this research.

\section{References}

Aaltonen, S. (2013). "Trying to push things through": Forms and bounds of agency in transitions of school-age young people. Journal of Youth Studies, 16(3), 375-390.

Berger, P., \& Luckmann, T. (1966). The social construction of reality: A treatise in the sociology of knowledge. Harmondsworth, Middlesex, UK: Penguin.

Berzin, S. (2010). Vulnerability in the transition to adulthood: Defining risk based on youth profiles. Children and Youth Services Review, 32, 487-495.

Cormack, D., \& Robson, C. (2010). Classification and output of multiple ethnicities: Issues for monitoring Māori health. Wellington, NZ: Te Rōpū Rangahau Hauora a Eru Pōmare.

Coulshed, V., \& Orme, J. (2006). Social work practice: An introduction ( $4^{\text {th }}$ ed.). London, UK: Palgrave Macmillan.

Evans, K. (2007). Concepts of bounded agency in education, work and the personal lives of young adults. International Journal of Psychology, 42(2), 85-93.

French, R., Reardon, M., \& Smith, P. (2003). Engaging with a mental health service: Perspectives of at-risk youth. Child and Adolescent Social Work, 20(6), 529-548.

Jones, J. (2011). Narratives of student engagement in an alternative learning context. Journal of Education for Students Placed at Risk, 16(3), 219-236.

Lerner, R., Almerigi, J., Theokas, C., \& Lerner, J. (2005). Positive youth development: A view of the issues. Journal of Early Adolescence, 25(1), 10-16.

Maschi, T., Smith Hatcher, S., Schwalbe, C., \& Rosato, N. (2008). Mapping the social service pathways of youth to and through the juvenile justice system. Child and Youth Services Review, 30(12), 1376-1385.

McLeod, A. (2007). Whose agenda? Issues of power and relationship when listening to looked-after young people. Child and Family Social Work, 12, 278-286.

Munford, R., \& Sanders, J. (2011). Embracing the diversity of practice: Indigenous knowledge and mainstream social work practice. Journal of Social Work Practice, 25(1), 63-77.

Munford, R., \& Sanders, J. (2015). Negotiating and constructing identity: Social work with young people who experience adversity. British Journal of Social Work, 45(5), 1564-1580. 
Office of the Children's Commissioner. (2015). State of care 2015. Wellington, NZ: Author.

Prior, D., \& Mason, P. (2010). A different kind of evidence? Looking for "what works" in engaging young offenders. Youth Justice, 10(3), 211-226.

Ruch, G. (2005). Relationship-based practice and reflective practice: Holistic approaches to contemporary child care social work. Child and Family Social Work, 10(2), 111-123.

Sanders, J., Munford, R., Thimasarn-Anwar, T., Liebenberg, L., Ungar, M., Osborne, A-M., ... Urry, Y. (2013). Methodological overview-The Pathways to Resilience Study. Palmerston North, New Zealand: Massey University.

Sanders, J., \& Munford, R. (2014b). Youth-centred practice: Positive youth development practices and pathways to better outcomes for vulnerable youth. Children and Youth Services Review, 46, 160-167.

Sanders, J., Munford, R., Liebenberg, L., \& Ungar, M. (2014a). Multiple service quality: The impact of consistency in service quality for vulnerable youth. Child Abuse and Neglect, 38(4), 687-697

Ungar, M., Liebenberg, L., Dudding, P., Armstrong, M., \& van de Vijver, F. (2013). Patterns of service use, individual and contextual risk factors, and resilience among adolescents using multiple psychosocial services. Child Abuse and Neglect, 37, 150-159. 